\title{
Evaluation of Questionnaire Data Views on the Design of Living Space for Different Situations in Life
}

\author{
Carsten Brausch a Dušan Katunský ${ }^{b}$ * and Jana Katunská ${ }^{b}$

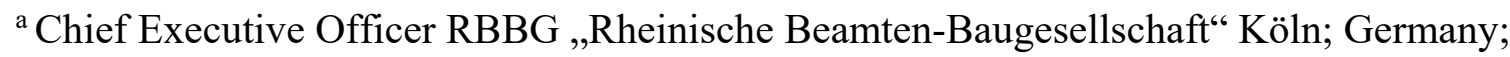 \\ brausch@rbbg.de \\ ${ }^{\mathrm{b}}$ Institute of Architectural Engineering, Faculty of Civil Engineering, Technical University \\ of Kosice, Slovak Republic; dusan.katunsky@tuke.sk; jana.katunska@tuke.sk,
}

*Corresponding Author: dusan.katunsky@tuke.sk

\begin{abstract}
The role of the submission was to find out what changes people think they need to make in their home because of getting older. At advanced age, the likelihood of different limitations such as vision impairment, hearing impairment or physical inability is increased. Currently, tenants are often forced to leave their long-term living space, as these spaces cannot serve "new" individual needs. This transition from the privacy of their home to the new environment often appears to be a painful change. They will not have a well-known environment because their homes cannot be adapted to their new needs. The aim is a comprehensive approach to the design of such an exterior and interior space which could serve people at all stages of their life, including the terms of mobility. This means that even if there is an unexpected situation and changes in movement abilities and physiological limitations of man, not only by natural aging, but according to accidents or disabilities we can adapt the living space to the given conditions. The survey results are presented in Germany and Slovakia. In the survey, respondents expressed their opinion on what they considered important in creating an adaptive environment considering various life changes. Results are processed graphically with explanation. The results could be of an interest to architects and designers of the environment. Based on the results of the questionnaire survey, studies of possible modifications of flats and houses were developed. The contribution brought these results to three age groups of respondents; people aged 35, 50 and over 50.
\end{abstract}

Keywords: interior design; questionare; life situation; data evaluation; different age groups

\section{Introduction}

According to UN statistics, currently, around 7 billion people inhabit the Earth. The average age of the population is steadily rising. While in 1950 , there were only $15 \%$ of people over the age of 65 in the population, it is estimated that by 2050, this figure will slowly reach half of the population [1]. Industrially developed countries will contain almost a third of them, themselves. Figure 1 shows the evolution of the population over the age of 65 in three parts of the world: developed industrialized countries, developing countries and the poorest countries in the world. The picture illustrates the situation over the course of a hundred years with a regard to the future, generally from 1950 to 2050 . It is clear from the picture that the proportion of the elderly population is constantly increasing.

The average age changes as well as people live longer. While in 1950, the average age of the world population was 23.6 years; in 2050 it will be 36.2 years [2]. An example of the evolution of the average age of the population in all parts of the world is shown in Figure 2, which is based on data [2]. Sometimes people have lived very briefly for known reasons (diseases, epidemics and wars). There are advances in lifestyle and health care, which should 
lead people to reach an average age of almost 50 years in the developed world in 2050. In the poor parts of the world it should be 28 years, while in poor countries it should be in time since 1950 to 2050 about 10 years of age. In developed countries it's almost double. This situation, of course, also concerns the European Union.

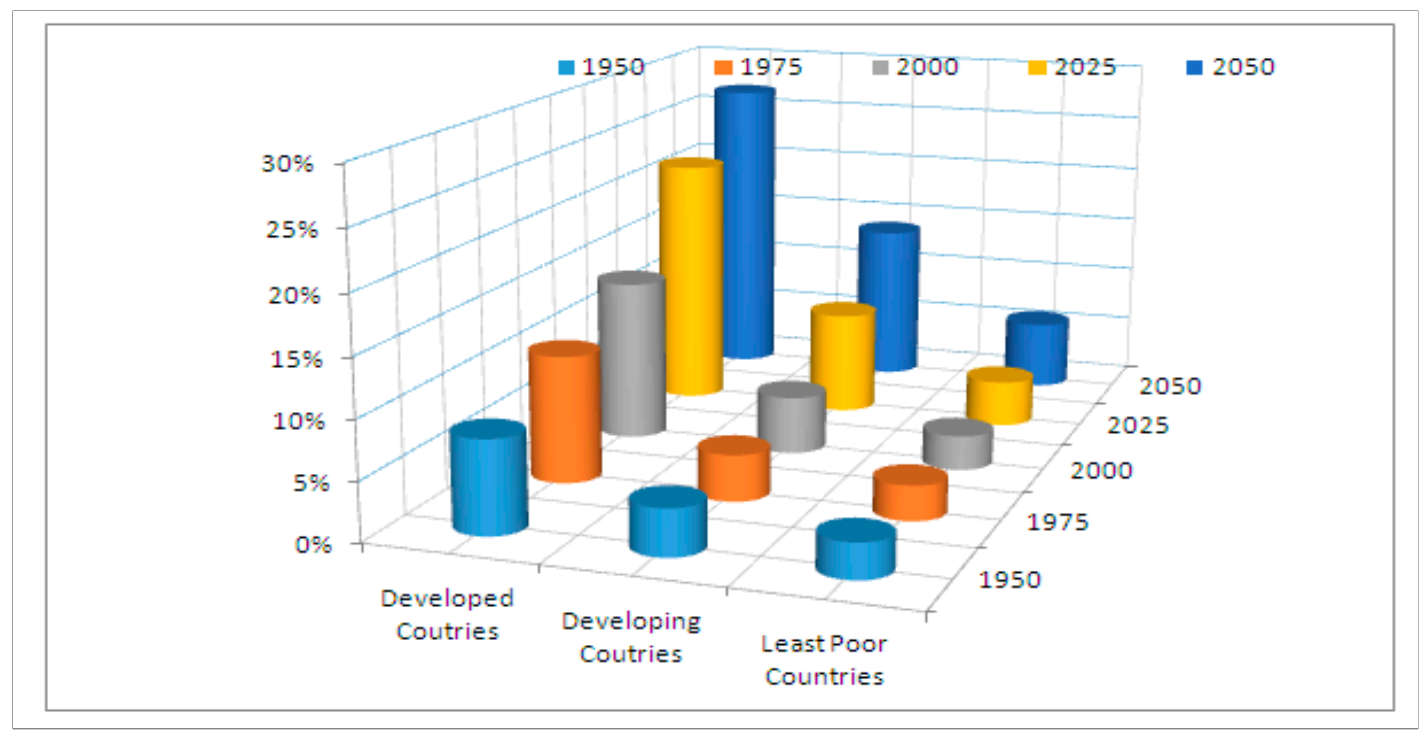

Figure 1 Growth of the population over 65 years of age in the world between 1950 and 2050 according to [1].

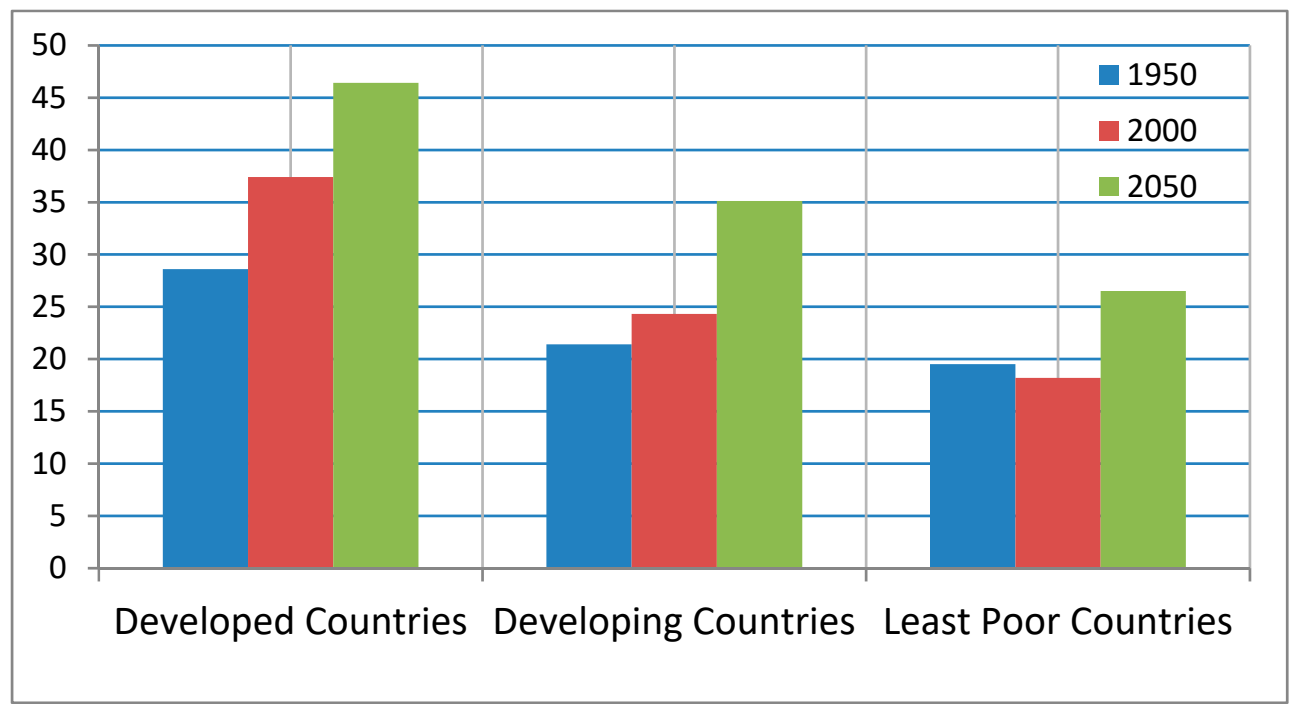

Figure 2 Average age of the population in the world according to [2].

Although there are industrially developed countries in the European Union (EU), lifestyle, living standards, national traditions are different in each country. In this article, we wanted to show some environmental aspects of creating life space for all phases of life. The EU is experiencing demographic change, resulting in a change in the social structure. People live longer and fertility decreases. Because people live longer, they are hardly moving away from their "native" home in an earlier period (in the autumn) of their lives.

This changing structure in Europe poses special problems for designers and apartment builders. A new approach to real estate design must be designed and implemented to suit the future [3] needs of people at all stages and to enable residents to remain self-sufficient in the "house" for as long as possible. At the earliest stages of the proposal, the typical requirements 
for each phase of the future citizens' future life must be considered. This is especially true for people with special needs of protection, such as those with visual or hearing disorders. Spaces for different phases of life were dealt with by many authors. Special requirements and rules based on considerations under the various regulations, in particular the Stockholm EIDD Declaration European Institute for Design and Disability [4] must be taken into account here.

In order to understand the situation of what people are thinking about and taking into account the different impacts in different life situations, we need to find them from different sources of literature and research. It is important that the survey highlights the importance of housing in European society. It is clear that the house is more than protection against climatic conditions and individual retreats for people and families. The way of living has changed in Europe. In most EU countries, it is necessary to anticipate barrier-free when designing the home or working environment [5].

It is not possible to compare the situation in the US, Asia, Australia with the situation in Europe in terms of housing. Everything depends on job opportunities and mobility for work. Europe consists of a number of countries that have their own national traditions and differ from each other by a different historical basis. Even in Europe, there are differences between the industrialized countries of Western Europe and the countries of Central and Eastern Europe that have had another historical development. In Europe, it is particularly typical to grow up in the birthplace, possibly returning home during life. It is also common for people to live in one house during their lives.

Moving home is a crucial step in gaining personal independence. People tend to get involved in designing their first home many times before it finally becomes reality. We anticipate the different needs and desires that we then have to adapt, given the hard constraints of space and money. We have to get rid of our "personal style".

The demographic trends change the social structure in Europe, changing the medium and long-term requirements for the development of residential users. For designers and homeowners, it would be good to calculate with these needs to avoid vacancies and to create customized living spaces that will allow residents to stay independent as long as possible in their own home [6]. Therefore, it is necessary to use the rules for a barrier-free living environment [7], [8] already in the proposal.

Demographic change is a primary issue, because it is becoming increasingly clear that this change will create a diverse society. Those who take decisions in national parliaments are called upon to take action and to think about the average age of a society, which on the one hand has a longer life expectancy, and on the other hand a lower birth rate. Statistically, the average life expectancy of newborns in Europe increases each year by two to three months. People not only live longer but also have increasing demands. In building industry, it is necessary to adapt and create new building systems and construction methods [9] and physical accessibility of buildings [10].

It is important to design buildings so that they are barrier-free in the living space. A review of current literature and related media quickly shows that the concept of accessibility is not clearly defined and is very versatile. Some differences in interpretation are caused by translation. The very concept of availability is not well defined, so a number of terms are used in the literature to represent it. Some terms are used for specific groups of customers, such as elderly people or people with disabilities. The concept of availability and demanding contemporary design is based on people's needs. The application of the terms used is illustrated in Figure 3, where a diagram of the association of individual terms can be seen. The behavior of a person during life is characterized by different life stages and life requirements. Architecture including barrier-free design, often works with concepts of green, sustainable design, green architecture, or design of low-energy buildings and the like [11], [12]. The latest results of the research on the design of barrier-free building environments are 
brought by Wang [13]. Various case studies have been published on living and environmental costs for seniors and people with disabilities [14]. Problems with special kitchen requirements for "ambient assisted living" were published by Blasco in Sensors [15]. Very interesting are Clark and Whitelaw's considerations about the importance of housing "Live well and die well" [16]. Some contributions point to the use of e-services for the elderly and the disabled in the interior space [17] or for the needs of transport in the exterior space [18].

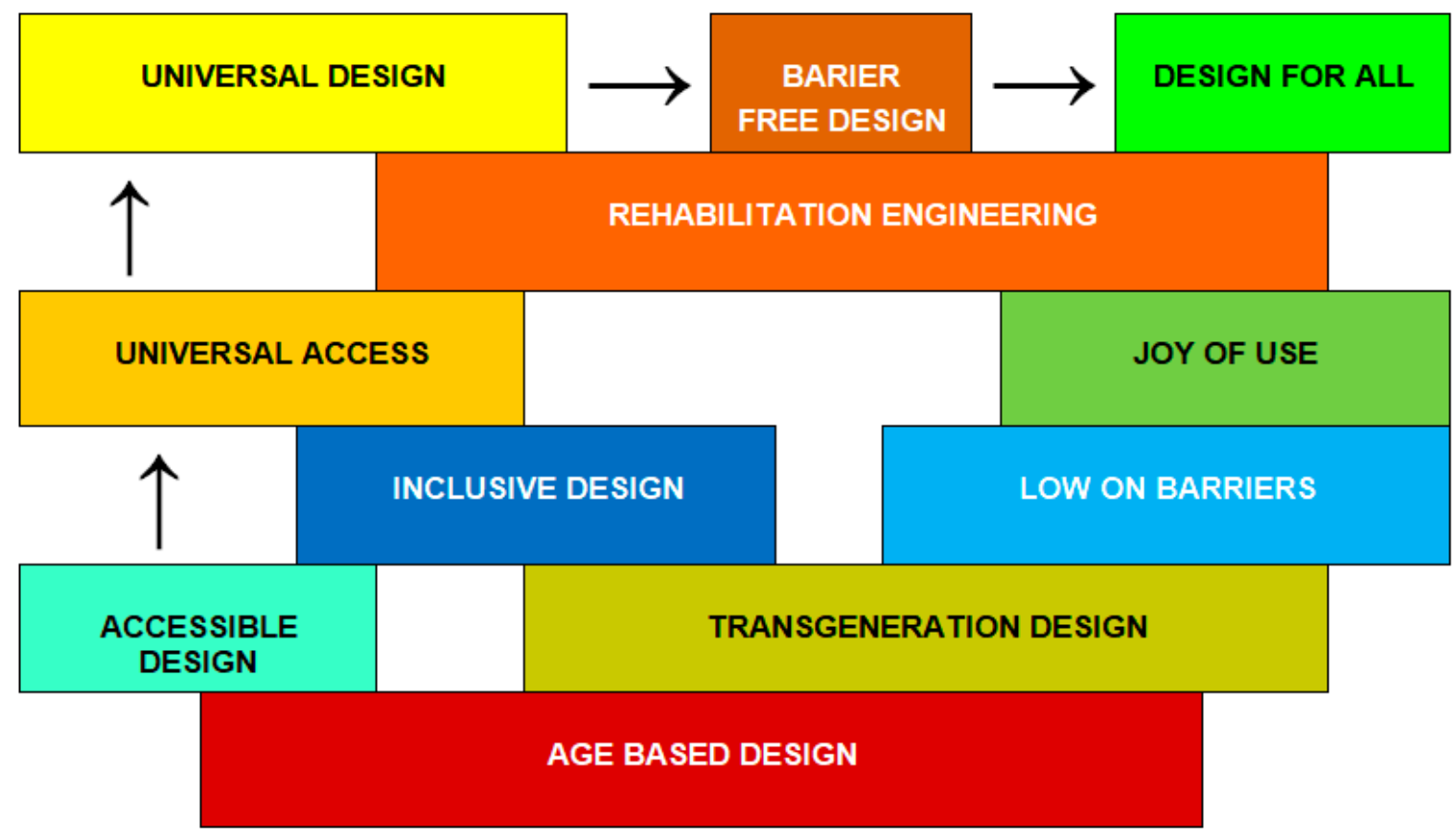

Figure 3 Tree of definition used (source author).

Universal design proposals for solving any barrier-free environment are described by Herwig [19]. Also, Kose deals with universal design on an international scale [20]. The summary of Georgieff's "ambient assisted living" [21] is also available in the digital library [22]. Suggestions for universal design in Scandinavia are described by Bendixen and Benktzon in Applied Ergonomics [23]. The benefit of such a proposal [24] is re-inventing existing real estate of social housing for older people [25]. Application and creation of furniture for a barrier-free environment for the elderly are presented by Zhang and Cheng [26].

The present situation is presented in the case study in Taiwan [27]. Other literary sources address the advantages, disadvantages, "discrimination" of a universal design of barrier-free environment [28]. The indoor environment for people with disabilities is presented in an interior study for Rio Grande, by Janner et al. [29]. The impact of a personalized active labor market program for people with disabilities is described in [30] Adamecz-Völgyi et al. Recently there is also a variety of information to help people with disabilities to improve their living situation. Barrusio published this year in Sensors [31] and Applied Sciences [32] about this issues. Kbar et al. [33] and Gilart-Iglesias et al. [34] deal with similar problems. Advantages and feasibility of a modular home design, for all phases of life, are processed by Brausch [35]. He has published partial results in [36], [37]. Suggestions for local rental of housing for seniors that improve their quality of life and selected aspects of integrated environmental management are addressed by authors in 2018 [38], [39].

\section{Aim and methods of research}


Aim of research was to find out what changes people think they need to incorporate to change their home because they are older. At advanced age, the likelihood of different limitations such as vision impairment, hearing impairment or physical inability is increased. Currently, tenants are often forced to leave their long-term living space, as these spaces cannot serve "new" individual needs. This transition from the privacy of your home to the new environment often appears to be a painful change. They will not have a well-known environment because their homes cannot be adapted to new needs. The aim is a comprehensive approach to the design of such an outside and inside space that could serve people at all stages of life, including the terms of mobility. This means that even if there is an unexpected situation and changes in movement abilities and physiological limitations of man not only by natural aging, but according to accidents or disabilities, we can adapt the living space. The survey results are presented in Germany and Slovakia. In the survey, respondents expressed their opinion on what they considered important in creating an adaptive environment in various life changes. Results are processed graphically with explanation. The results could be of interest to architects and designers of the environment. Based on the results of the questionnaire survey, studies of possible modifications of flats and houses were developed. The contribution brought these results to three age groups of respondents; people aged 35, 50 and over 50 .

As a method of research in this area, a questionnaire survey was conducted in two European countries in Germany and Slovakia. Questionnaires were distributed by both authors. It was in most cases a university environment, where the age group ranged in students and young scientists up to 35 years of age. Another group was under the age of 50 and then over 50 years. For this purpose, the questions were also selected. It is usually the answer where the respondent chooses whether the subject matter is important to him, less important, and so on. Alternatively, choose one of the possible response variants. From the fact that respondents were mostly from university, most of the questionnaires were received from people under the age of 35, about half of them. A smaller group was aged 35 to 50 and about a third was over 50 .

As mentioned above, in the field research, questionnaires were distributed to people of different ages; both in Germany and Slovakia. In Slovakia and Germany, a lot of questionnaires were distributed, 60 were evaluated in Slovakia and 60 in Germany, which is 120 respondents together. It is not possible to precisely specify the statistical analysis, nor was it the subject of the research. Questions are so specified that not all options are pre-established and many responses are based on subjective feelings and subjective opinions. There are several dozen situations in one answer.

The survey provides an overview of the information and needs of people of different ages on housing and living space in two different countries (developed in the western EU country Germany and the eastern new EU country Slovakia). Based on responses to 13 questions, opinions can be made on options, needs and ways of housing. The analysis of the results provides an explanation of the needs and commercial viability of a modular and flexible living space design for all phases of life. The answer to the questions of the subjects was carried out without a specific introduction to the topic of demographic change and their implications for the design of the living space. The main questions in the questionnaire are given in Table 1.

Table 1 Basic questions of questionnaire

\begin{tabular}{ccc}
\hline 1 Which age group do you belong to? & more than 50 years \\
up to 35 & 35 to 50 years & \\
years & No \\
Yes & From your current perspective, would the possibility of a modifiable floor plan represent added value? \\
\hline
\end{tabular}


3 How important is it for you to be able to stay in your current living quarters in spite of changing living situations?

$\begin{array}{ccc}\text { Very } & \text { Important } & \text { Less } \\ \text { important } & \text { Important Important }\end{array}$

4 Which changes in living circumstances can you think of that require an adaptation of your individual living space?

Answer

5 Which changing living circumstances could you foresee in the future requiring an adaptation of your living quarters?

Answer

6 Do your current living quarters allow a variable reconfiguration of the rooms?

$$
\text { Yes No }
$$

7 In how far are you willing to pay a higher rent for an adaptable/barrier free living space? How many percentage points can the costs be above the current market value of a not adaptable/barrier free living space?
$0 \%$
up to $10 \%$
$10 \%$
more than $20 \%$ $20 \%$

8 Which criteria are important for you in a good living area?
Doctors
Shops for daily needs
Sports facilities
Green areas forest
Cultural offers
Public transport
School kindergarten
Pool
Restaurant, cafe
Playground

9 Which importance do you attach to which furnishings when choosing your individual living quarters?

No thresholds, Balcony/Terrace, Bathroom with plane, Shower tub, Elevator

in Building, Sufficient movement possibilities, Emergency call system,

Parking space, Others

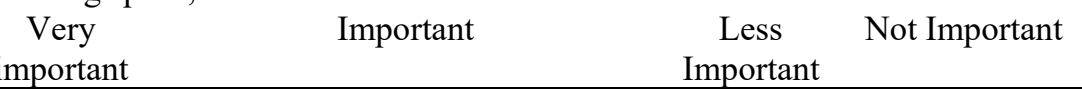

10 How important are potential service offers to you?

Food/Catering, Transportation services, Care services, Shopping assistance, Others

\begin{tabular}{|c|c|c|c|}
\hline $\begin{array}{l}\text { Very } \\
\text { iportant }\end{array}$ & Important & $\begin{array}{c}\text { Less } \\
\text { Important }\end{array}$ & Not Important \\
\hline
\end{tabular}

11 Which technical supports are of special importance to you?

Answer

12a Which of the below-mentioned points are of special importance for you?

Step-free entrance, Sufficient movements possibilities, Covered Entrance, Clear door width, Broad parking slots, Emergency call system, Others

$12 \mathrm{~b}$ Which prioritization would you give to these points? Answer

13 Is there anything else you would like to mention as important for the longest possible stay in your own living quarters?

Answer

The results obtained and the data from the survey were statistically processed using the statistical statistic statistical analysis tool Statistics 12 using the Chi-quadratic test method. The choice of data evaluation methods was based on the individual typology of questions and answers.

\section{Discussion and results}

In the following sections, we show the answers to questions in the questionnaire. In order to reconcile the situation and the possibility to compare the responses or the case study group, 
only the percentages of the total number of responses are listed. No absolute figures are given because the results would not be conclusive. The following statements can be taken on individual questions and the results can be evaluated as follows.

\section{Question 1: Which age group do you belong to?}

The answers to the first question allow you to divide the respondents into three age groups. This differentiation is important for analyzing some issues, as it is to be expected that different age groups expect different living situations in the future and will have priorities for other requirements. In particular, it is expected that there will be differences between the age groups in response to the question of, for example, expected technical aids. Three age groups were provided:

- Up to 35 years

- 35 to 50 years

- More than 50 years

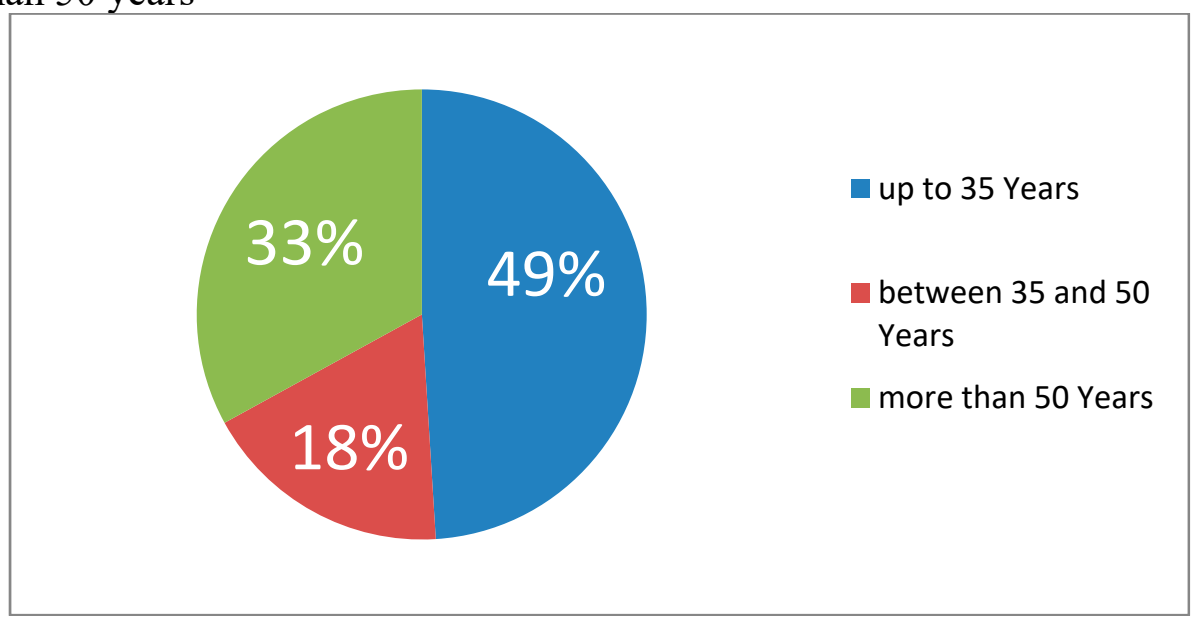

Figure 4 Classifications in age groups, participants of questionnaire in percent.

\section{Question 2: From your current perspective, would the possibility of a modifiable floor plan represent added value?}

In the second question, the participants were asked if the possibility of a modifiable floor plan would represent additional value from their current perspective. $95 \%$ of the participants responded "yes"; only 5\% responded "no". This result shows the awareness within society and the expressive desire for a flexible, adaptable living space and the resulting demand for such. It can be assumed that the participants will choose in a future change of living space a flexible floor plan over a fixed one, at least as long as the other prerequisites are similar.

\section{Question 3: How important is it for you to be able to stay in your current living quarters in spite of changing living situations?}

The responses to this question clearly show (as they do in question 2) the wish of the participants to remain in their living space as long as possible. For the real estate agent, this means that if he or she offers a flexible, adaptable building suitable at all phases of life, sustainable marketing and long-term stay of the user is likely.

If one combines the results for the replies very important and important, $91 \%$ of participants wish to remain between their own four walls. Analysis of the responses shows that the replies less important and unimportant are rarely used. Only $7 \%$ consider the possibility to remain in their own living space to be less important and $2 \%$ unimportant.

These results are schematically illustrated in the following Figure 5. 


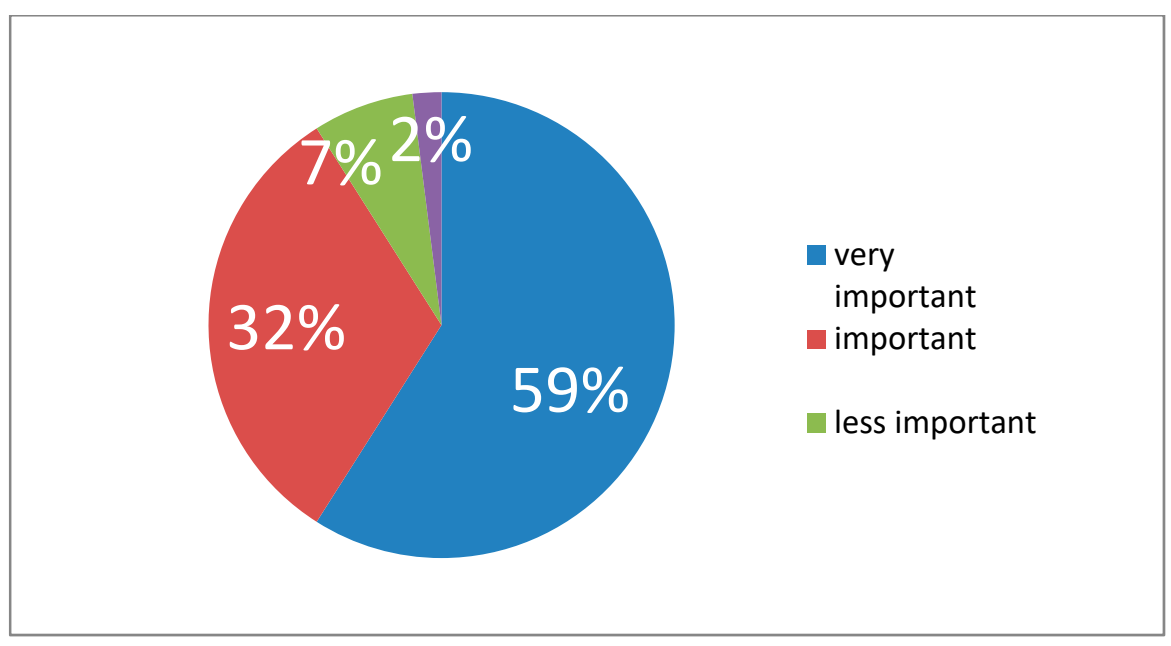

Figure 5 Ability to stay in the current living quarters.

\section{Question 4: Which changing living circumstances can you think of that require an adaptation of your individual living space?}

In the responses to this question, several circumstances are mentioned by the various age groups depending on the phase of life. Those below 35 years of age often mention planning for a family or changes in the employment situation. Those between 35 and 50 consider that children will leave home soon. Those above 50 no longer require office rooms and consider the upcoming need to take care of sick or disabled relatives. All these criteria have a direct effect on the space requirements. It is very interesting that all age categories characterize the accident, which can change their lifestyle. They pay great attention to the accident. People aged to 35 and up to 50 speak of the disease, while respondents aged over 50 years already describe specific diseases, limitations, actual barriers to visual impaired, hearing impaired, walking difficulties, etc.

\section{Question 5: Which changes in living circumstances could you foresee in the future requiring an adaptation of your living quarters?}

The responses to questions 4 and 5 were analyzed together. There were many and many situations which required making decisions about a change of life and a need to change the living space. Representative responses were selected. It is useful here to separate the answers by age group. This is shown in Table 2 .

Table2. Informatively separated responses by age group

\begin{tabular}{ccc}
\hline Age up to 35 & Age 35 to 50 & Age more than 50 \\
Marriage & & Visually impaired \\
Child & Becoming elderly & Hearing impaired \\
Economic improvement & Increase of disability & Walking difficulties \\
Illness & Sudden illness & Physical disability \\
Accident & Caring for relatives in need & Loss of partner \\
Job change & Accident & Dementia \\
& Issue of child & Personal nursing \\
& & Room of no longer needed \\
\hline
\end{tabular}

\section{Question 6: Do your current living quarters allow a variable reconfiguration of the} rooms? 
Of the all participants there are $54 \%$ answer yes and $46 \%$ no when considering whether their current living space is flexible. However, it must be borne in mind that the interpretation of flexible can vary considerably. There are different situations in Slovakia and in Germany. See Figure 6.

Remarkable in analyzing the data for this question were the various reactions between Slovak and German participants. It was found that $80 \%$ of participants from Slovakia consider the current living space to be variable but only $27 \%$ of German participants consider their current living space to be variable. It may just be speculated that Slovak participants are more willing to renew. Another possible explanation could be the skeleton buildings that have been built in Slovakia in recent decades, which have already formed the basis for flexible construction (skeletons, panel houses, apartment buildings). These buildings allow greater flexibility compared to other types of construction. Thanks to this construction style, the structural weight of buildings is predominantly operated by columns, panels and ceiling slabs. Supporting walls that are not replaceable or replaceable only with great effort are rarely present in this building style.

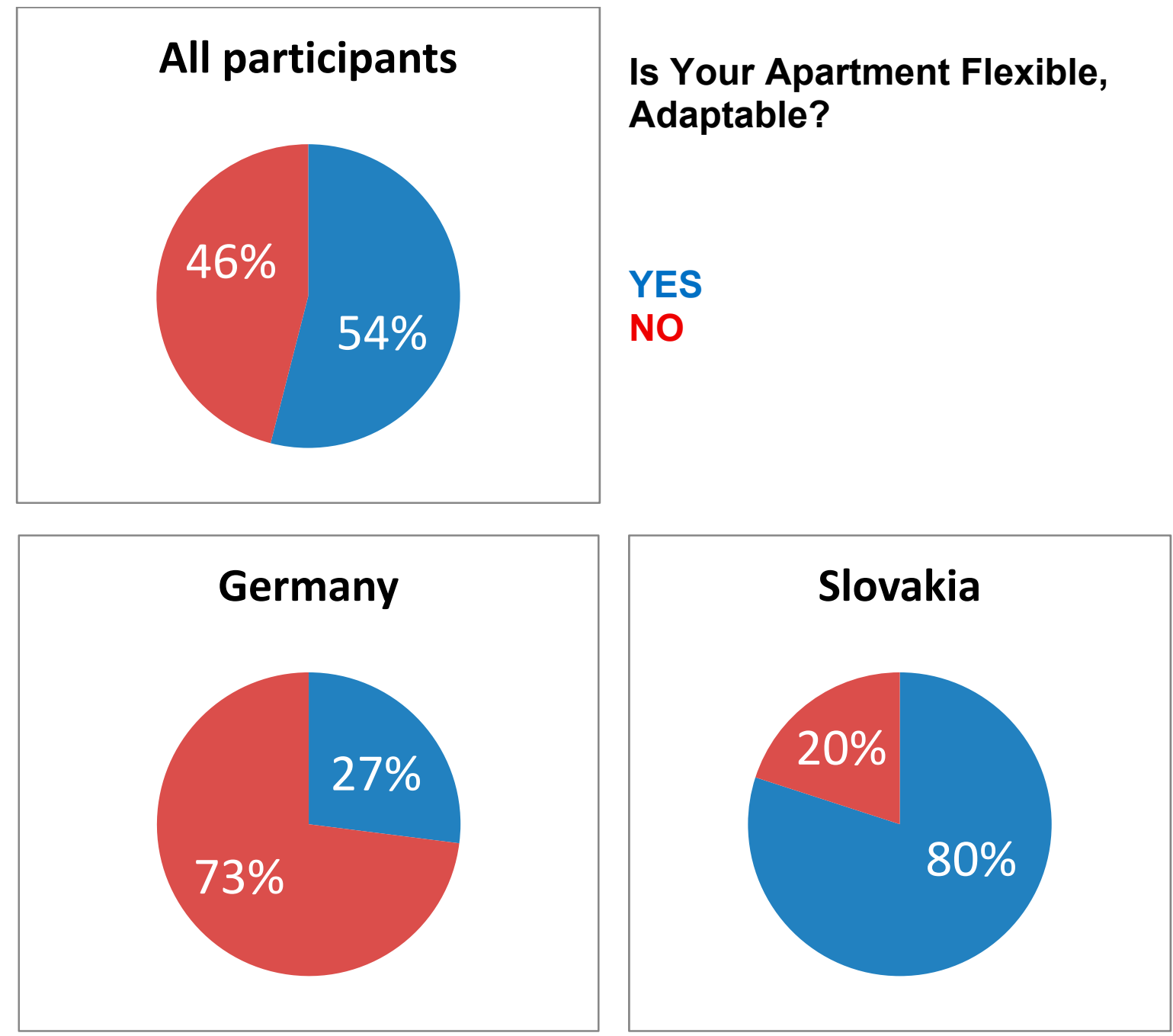

Figure 6 Is your apartment flexible, adaptable?

In Germany, predominantly atypical buildings (not blocks) have been built, which can be more difficult to adapt to new needs. That's why people think their living space is not flexible. 


\section{Question 7: In how far are you willing to pay a higher rent for an adaptable/barrier} free living space? How many percentage points can the costs be above the current market value of a not adaptable/barrier free living space?

How important the participants consider a flexible and barrier-free living space can be seen by their willingness to pay a higher rent.

Only approximately $12 \%$ of the participants are unwilling to pay a higher rent or costs for a variable and barrier-free living space compared to an inflexible one. About $40 \%$ of the participants would be willing to pay up to 10 percentage points more and another $40 \%$ up to 20 percentage points more. Approximately $8 \%$ were even willing to pay more than 20 percentage points more than the standard price. With this willingness to pay more for a barrier-free and variable living space, the users declare the value of these advantages. Surely this outcome also mirrors the knowledge that the increased construction efforts come with increased costs.

Calculated for the overall time of inhabiting a building, the initially higher costs are certainly less than the sum of the necessary rebuilding (if possible at all). This analysis can be seen in Figure 7.

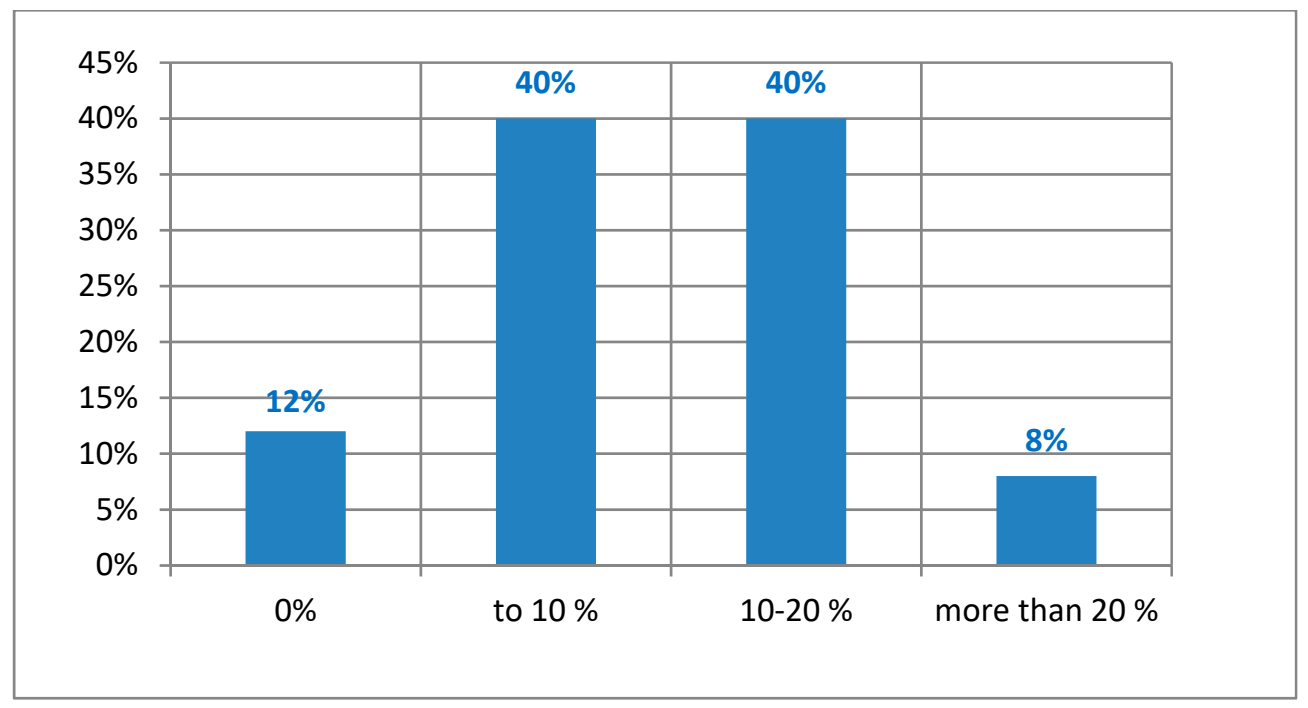

Figure 7 The willingness to pay a higher rent for an adaptable living space.

\section{Question 8: Which criteria are important for you in a good living area?}

In this question seven parameters defining the location of the living space were provided, multiple answers were possible. In addition, a free text answer was possible under "other".

The results show clearly how important outside areas such as gardens and forests are for the users. The need to move in nature is major. This is also confirmed in the other questions where many participants wish for a garden, balcony, or terrace. At the same time, a central location is also of importance. The presence of medical doctors, shops for daily needs, and an efficient connection to public transport are considered as a part of a good living location. The availability of a school and kindergarten is considered necessary by the younger participants.

In the following questions the participants from the higher age group also request a crossgenerational living space and a mixture of inhabitants of all age groups. As additional parameters a pool, cafe/restaurant, and playground were mentioned. This analysis can be seen in Figure 8. 


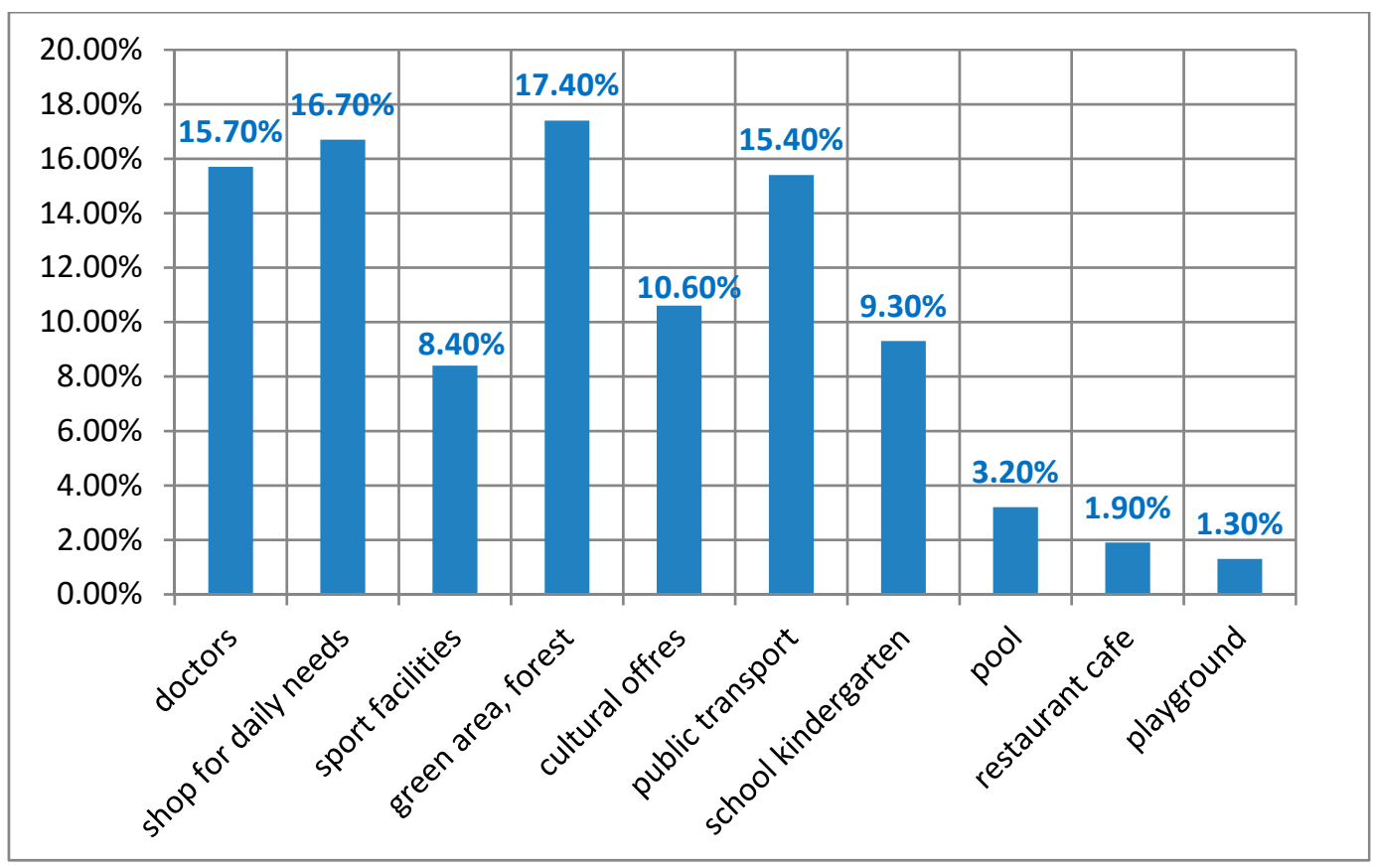

Figure 8 Criteria for a good living area.

A detailed analysis according to age groups confirms the results obtained so far. All responders below 35 and above 50 consider green areas-gardens, parks, forests-very important for the choice of the location of their homes. All four criteria shown are considered to be very important.

This clearly shows the desire to live in a functioning infrastructure with an efficient public transport system, and this across all age and life phases. The house builder is well advised to consider all these criteria during the planning and building of a living space.

Of all the possible criteria, the respondents considered four criteria (shops, transport, green areas, and doctors) the analysis of which by age groups can be explained as follows. Results of statistical significance testing $(p<0.05)$ recorded statistically significant differences between the comparator groups of respondents in terms of their age categories (Chi-square $=$ 29.19; $\mathrm{df}=6 ; \mathrm{P}<0.0001)$. This shows that the different age categories of respondents have different priorities in the evaluated parameters. It can be seen in Figure 9.

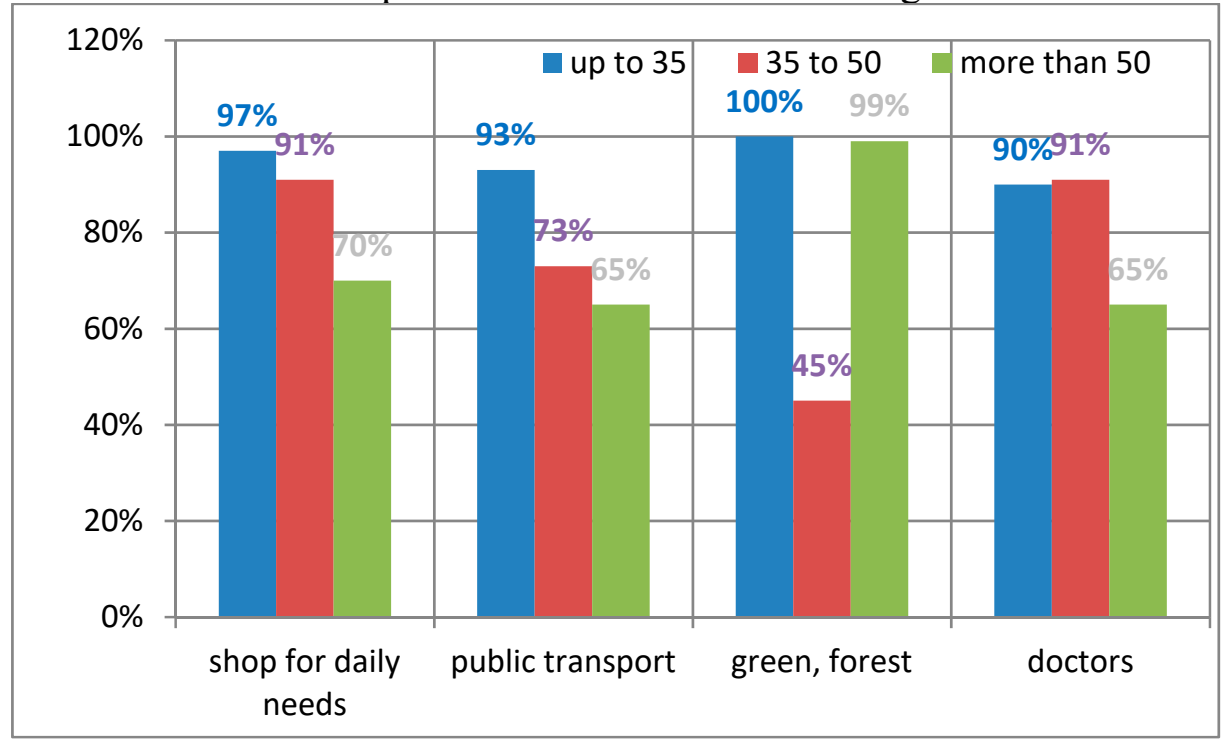

Figure 9 Criteria for a good living area by age groups. 


\section{Question 9: Which importance do you attach to which furnishings when choosing your individual living quarters?}

This was a multiple choice question. The responses show which fittings are of special value to the participants. Seen to be of high value is the presence of a bathroom with a ground level shower stall, which is an excellent example of a demand that is independent of the age range and provides an advantage for all. Likewise, the availability of a balcony or an outdoor sitting area is in high demand. If necessary, it is of important for the users to have an alarm system at their disposal, which shows the demand for a secure living space.

The level constructions of the rooms with a sufficiently large area for keeping strollers, bicycles, walking frames, wheel chairs, etc. are considered important as well, which should be considered in the planning and construction of barrier-free living space. The presence of an elevator is another major item. If not initially available in a building, the construction should take into account a potential to retrofit an elevator. Remarkably, these features are in demand independently of age, which shows that barrier-free equipment has advantages for all. Analysis can be seen in Figure 10.

Elevators and bathrooms seemed very important to all age groups. Lower age groups up to 35 would prefer a shower cubicle. The age group of 35-50 of all responses did not consider the area of the balcony as important because of the fact that most of the time they are present at work and the apartment is coming later. Even when determining the priorities of the emergency call system for the age group of 50 and over 50, they responded similarly to the age group up to 35, which does not consider this system to be so important. The results of statistical testing at the level of significance $(p<0.05)$ recorded statistically significant differences between the comparator groups of respondents in terms of their age categories (Chi-square $=58.60 ; \mathrm{df}=6 ; \mathrm{P}<0.0001)$. This shows that the different age categories of respondents have different priorities in the evaluated parameters.

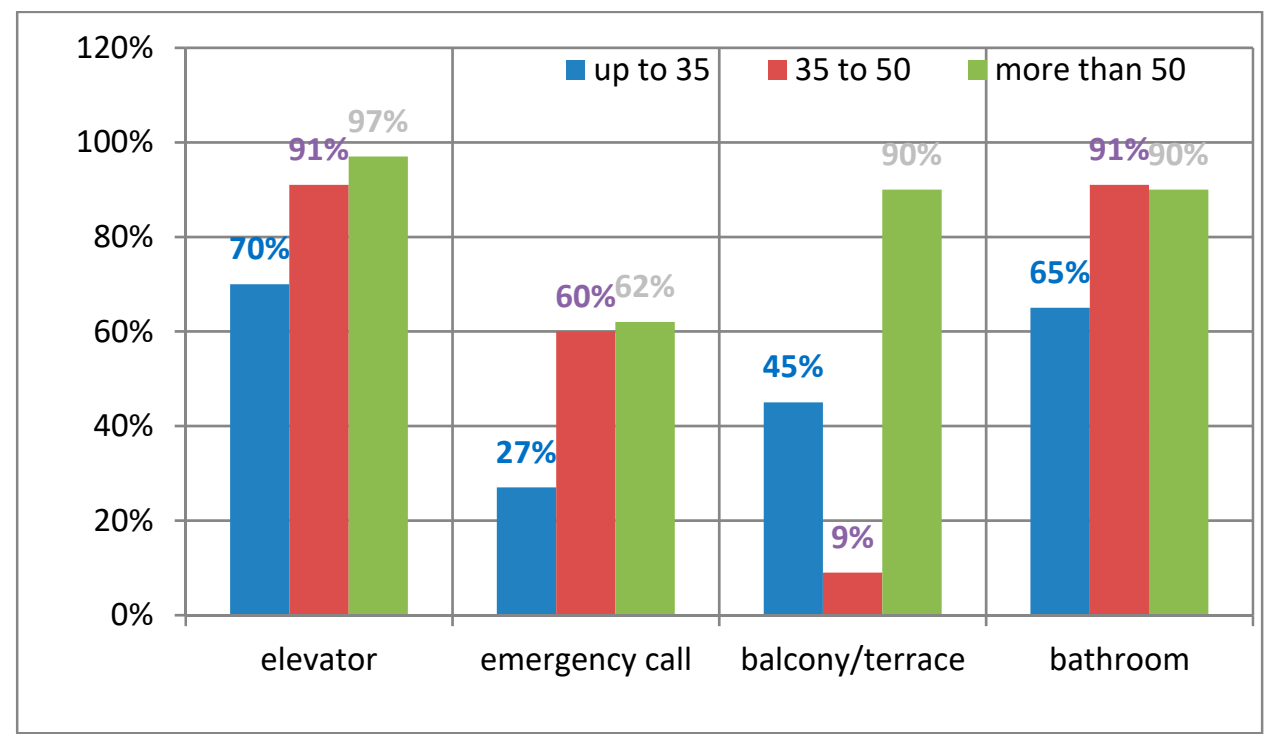

Figure 10 Importance's for choosing the individual living quarters by age groups.

\section{Question 10: How important are potential service offers to you?}

The question regarding the importance of potential service offers was answered as follows:

When assigning the relative importance of the questions, multiple answers were possible. Assessment of the different age groups shows the specific priorities. Those below 35 consider 
the food/catering, care services, and transport as very important. Obviously, what they currently consider a luxury is often later considered as a defined need. However, this age group is also sufficiently forward-looking to consider care services as very important. The group between 35 and 50 is less clear in considering something as very important. Relative importance is given to catering, care, and shopping services. The group above 50 considers the care services as most important. The other services are not seen as very important. Participants also mentioned cleaning and laundry services as well as support for garden/outdoor area work. This analysis can be seen in Figure 11.

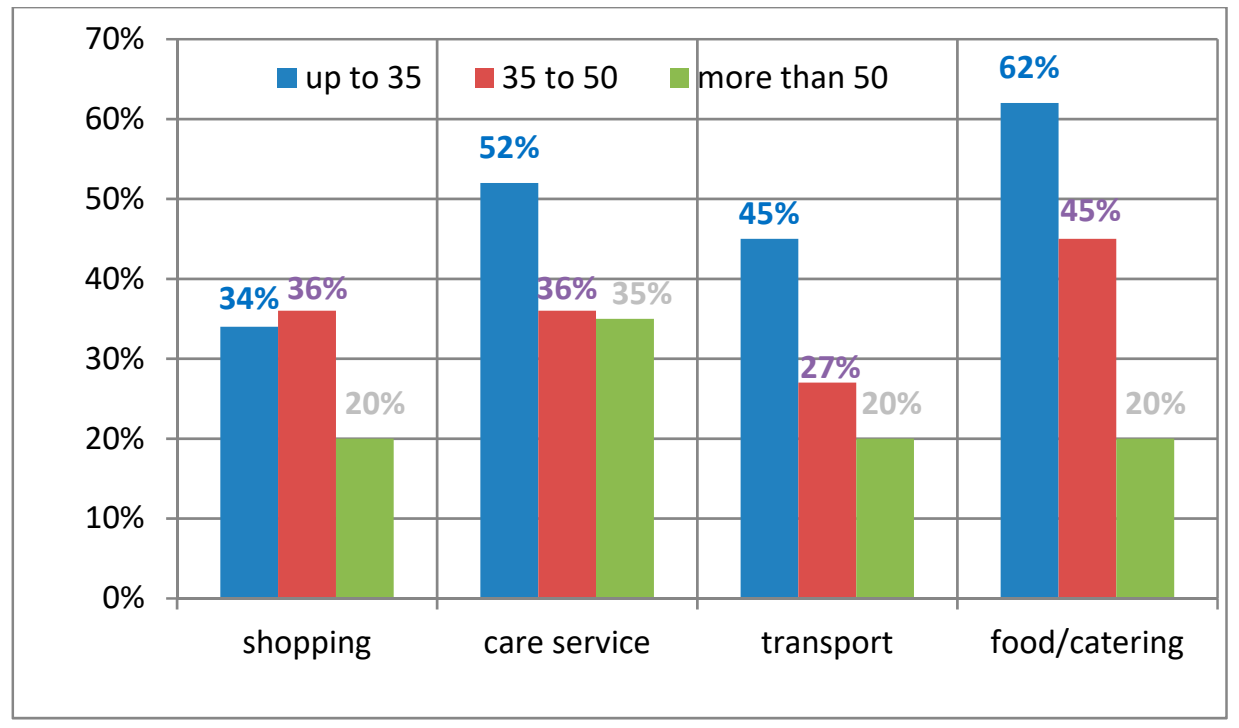

Figure 11 The demand for potential service offers by age groups

Results of statistical testing at the level of significance $(\mathrm{p}<0.05)$ did not show statistically significant differences between the comparator groups of respondents in terms of their age categories (Chi-square $=8.984 ; \mathrm{df}=6 ; \mathrm{P}=0.1745$ ). Based on a more detailed analysis, some local differences between the groups of respondents were noted, but differences were not statistically significant. Consequently, the individual age categories of respondents do not have significantly different priorities in the evaluated parameters. Planners and designers should, early on, make potential tenants aware of the service offers available. Finally, it has to be mentioned that these services are not provided by the landlord, but can be significant criteria in the choice of the location for a dwelling and can be a competitive advantage.

\section{Question 11: Which technical supports are of special importance to you?}

This question did not provide answers to choose from, but provided an opportunity to voice the personal needs of the participants, who named the technical aids of special importance to them.

The following technical aids were mentioned: High speed Internet access, Television access in several rooms, Environmental control, AAL, ground level shower stall, Raised lavatory seat, Elevator, Emergency call, Bath tub lift, Stair lift, Electronic window shutters, Height adjustable bed, etc. What importance has been given to the technical aids of the individual age groups of the survey participants can be seen in Table 3 . We do not have information, nor can we know how many of the participants defined the technical aids of the individual age groups. 
Table 3 Technical supports - Informative to separate the responses by age group

\begin{tabular}{ccc}
\hline Age up to 35 & Age 35 to 50 & Age more than 50 \\
\hline & & Elevator \\
High Speed & Elevator & Stair Lift \\
Internet Access & Stair Lift & Bath Tub Lift \\
TV & Bath Tub Lift & AAL \\
& AAL & Emergency call systems \\
& & Raised lavatory seat \\
& & Height adjustable bed \\
\hline
\end{tabular}

The responses show a degree of basic knowledge about the potential technical aids available. Some technical aids for the realization of barrier-free living space, like the stair lift, are mentioned several times. Other demands are described by the desired function, like the environmental controls. Separated by age groups, it can be seen that those below 35 mostly name the Internet, TV. Those between 35 and 50 as well as those above 50 mostly select elevator, Raised lavatory seat, stair lift, bath tub lift, emergency call systems, height adjustable bed and AAL. Those above 50 also chose handles in the bathroom and heightadjustable beds. Throughout the whole questionnaire, well-known technical aids like stair lifts or bath tub lifts are named.

It can be seen that there are demands which can be added with relatively little effort, but also some which have to be considered early on in the planning and construction phase. In the meantime, many more innovations are available on the market.

\section{Question 12a: Which of the below-mentioned points are of special importance for you?}

It can be seen that all suggested items are considered important by the participants. The most frequently mentioned items are clear door width and emergency call systems. A wellilluminated entrance area was also mentioned, which is an important note that should not be forgotten. By the high value placed on the above answers, the participants display a comprehensive awareness of barrier-free living space, or living space for all phases of life. Of all possible answers, six priorities emerged. The percentage representation of participants' importance can be seen in Figure 12.

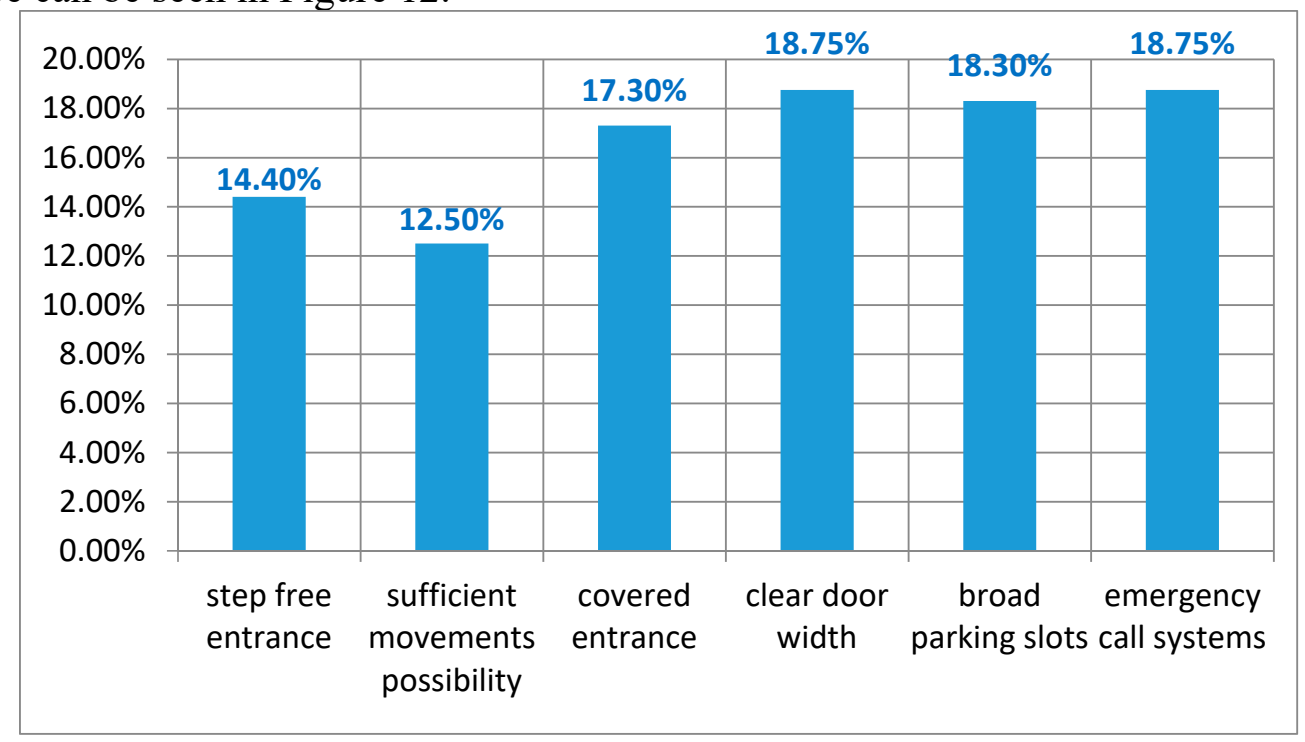

Figure 12 Items of special importance. 


\section{Question 12b: Which prioritization would you give to these points?}

The analysis of the prioritization shows that clear door width and emergency call systems are considered to be the most important. For the second most important item, the answers are country-specific, with the Slovakian participants mentioning broad parking slots and the German participants mentioning clear door width. In the third place, a covered entrance, step free entrance and sufficient movement areas are mentioned. All responses range closely together, which shows that all of these points have to be considered in the realization of barrier-free design for all phases of life living space.

\section{Question 13: Is there anything else you would like to mention as important for the longest possible stay in your own living quarters?}

This free-text question provides an opportunity for the participants to name important points not specifically included. Importance for the longest residency in their own residential neighborhoods - see Table 4 for all age groups. The following points were mentioned:

Table 4 Importance for longest possible stay in your own living quarters - for all age groups

\begin{tabular}{cc}
\hline Age up to 35 & Age more than 50 to 50 \\
\hline Good neighborhood & Clean, well-tended surroundings \\
Good location & Family contact \\
Home care & Cross-generational living \\
Preservation of independent living & Intercom with video screen \\
Room for visitors \\
Potential for private retreat \\
Well-being
\end{tabular}

Here, the importance of the location and surroundings is stressed again. Besides the demand for a green environment and sufficient infrastructure, the participants place high value on well-tended surroundings and a good neighborhood. One participant referred to this as well-being. High priority is given to privacy and the preservation of independence.

\section{Conclusions}

Optimization results from the questionnaire evaluation show that participants have a high level of awareness of the different stages of life and resulting changes in the life situation. Different age groups expect specific changes in the life situation. Planning parenting is often a key aspect for people under 35 while people aged 35-50 often consider moving an adult child or relocating a relative in need of help more likely. Group over 50 years of age are most concerned about possible health disorders and have knowledge of possible solutions. This group has changed in recent years - the number is rising and often in good financial condition, they are an important goal for the real estate market. No longer satisfied with a small oneroom flat, more than 50 year olds prefer flexibility, innovations, and independency.

The responses in the questionnaires clearly show the age-specific needs and uncover a multitude of varying expectations. The number of potential occurrences increases the likelihood of changes in living situation. Only an adaptable and flexible changeability of living space can then assure the possibility to remain in one's own dwelling for a long time. If you consider this investigation as a basis for planning and the requirements mentioned, a good guideline for the design of barrier-free and flexible living space can be drawn up. The desk 
research has already shown the demand for variable, flexible living space. This field research confirms this and stresses the need for barrier-free, flexible living possibilities.

Health is not considered to be obvious and is considered to be very valuable. Most people, however, have avoided interconnecting the changing situation and resulting needs with age or disability. Everyone has a well-developed, individual sense of what is good for them and what personal gain is.

Similar principles apply to interior design. If possible, we will inform you in other articles about the possibility of realizing the flexibility of the ground plan, the design of the flats for the barrier-free apartment type will be explained in the examples below. In addition to suggestions for people with impaired movement, consideration should be given to suggestions for individuals with sensory abnormalities. The approach described in the rules is the principle of two senses. In addition to visual cognition (tactile), tactile (touching) and auditory (hearing) knowledge is also used. The two-sided principle says that if two of the three senses are solved in the building, it is considered as barrier-free for $90 \%$ of all users.

In the future, it will be possible to activate the building, meaning that buildings will be able to communicate with people using digital information to understand the barriers present. The aim is to enable all individuals to use their living space without difficulty and, most importantly, without external assistance, by incorporating a barrier-free design.

The World Health Organization (WHO) has developed a classification to describe the functional health status, type and degree of disability, social disadvantage and relevant environmental factors under the heading "International Classification of Functioning, Disability and Health (ICF)". A disability in the context of the ICF is the result of negative interaction between a person with a health problem and contextual factors on that person's ability to function. The ICF term disability is thus the generic term to cover any form of impairment. For architects, designers, environmentalists, the task is to create a living space in which people can stay as long as possible throughout life, in all its phases.

Acknowledgement: This contribution was developed in connection with the research project VEGA 1/0674/18 of the Scientific Grant Agency of the Ministry of Education, Science, Research and Sports of the Slovak Republic and Slovak Academy of Sciences.

Author contributions: Dušan Katunský wrote the article, distributed a questionnaire in Slovakia and evaluated the results of some data, made conclusions. The author of the questionnaire is Carsten Brausch, who distributed the questionnaire in Germany and evaluated the results. Jana Katunská participated in the evaluation of some graphical and statistical analyzes. All authors communicated when evaluating the results and mutually endorsed the results and procedures.

Conflicts of Interest: The authors declare no conflict of interest.

\section{References}

1. United Nations Population Division World population prospects: The 2002 Revision. 2003 available at: http://www.un.org/esa/population/publications/wpp2002/WPP2002-HIGHLIGHTSrev1.PDF

2. Brown, L. R.; Gardner, G.; \& Halweil, B. Beyond Malthus: The Nineteen Dimensions of the Population Challenge. Routledge 2014.

3. Birg, H. Die Weltbevölkerung-Dynamik und Gefahren. Beck'sche Reihe Wissen, Nr. 2050. 1996.

4. European Institute for Design and Disability, Stockholm EIDD Declaration. 2004, Sweden

5. Katunský, D.; Lopušniak, M. Interaction of selected parameters within design of suitable working environment, in: HB 2006 - Healthy Buildings: Creating a Healthy Indoor Environment for People, Proceedings 3, Lisboa 2006, pp. 147-152.

6. $\quad$ Chen-xiao, L. I. Discussion on Barrier-free Design. Packaging Engineering 2007 (3) 048.

7. Ngowi, A. B. Creating competitive advantage by using environment-friendly building processes. Building and Environment 2001 36(3) 291-298. 
8. Pernišová, A. Proposal of architectonic-construction solution of barrier-free measures of entry premises in non-residential buildings specified for use by the public. Applied Mechanics \& Materials 2016, 820.

9. Baghchesaraei, O. R.; Baghchesaraei, A. Creativity and Innovation in Building Systems and Construction Methods 3. th International Congress on Civil Engineering, Architecture and Urban Development, Tehran(Iran); 12/2015

10. Ondra, S., Červenka, P., Hanousková, M., \& Sobol, K. Web Guide to Physical Accessibility of Buildings. Universal Learning Design, Linz 2016, 73.

11. Bielek, B., \& Bielek, M. Environmental Strategies for Design of Sustainable Buildings in Technique of Green Eco-Architecture. Central Europe towards Sustainable Building, Prague, 2010, 81-84.

12. Bielek, M.; Bielek, B.; Híreš, J. Technology in Architecture - Low Energy Building versus Green and Sustainable Building, Advanced Materials Research 2013, Vol. 649, pp. 207-210,

13. Wang, H.; Deng, H. Research on Barrier-free Design of House Environment, International Conference on Advances in Social Sciences and Sustainable Development (ASSSD 2018) Fuzhou, China on April 2018

14. Lewandowska, A.; Branowski, B.; Joachimiak-Lechman, K.; Kurczewski, P.; Selech, J.; Zablocki, M. Sustainable Design: A Case of Environmental and Cost Life Cycle Assessment of a Kitchen Designed for Seniors and Disabled People. Sustainability 2017, 9, 1329.

15. Blasco, R.; Marco, Á.; Casas, R.; Cirujano, D.; Picking, R. A Smart Kitchen for Ambient Assisted Living. Sensors 2014, 14, 1629-1653.

16. Clark, D., \& Whitelaw, S. Living well, dying well-the importance of housing. European Journal of Palliative Care 2017 24(5), 199-202.

17. Galajdova, A.; Simsik, D.; Dolina, Z. Testing of e-services for seniors and people with disabilities within e-inclusion project MonAMI. International Journal of Rehabilitation Research, 2009 (32), 75-76.

18. Zhou, H.; Hou, K.-M.; Zuo, D.; Li, J. Intelligent Urban Public Transportation for Accessibility Dedicated to People with Disabilities. Sensors 2012, 12, 10678-10692.

19. Kose, S. From barrier-free to universal design: an international perspective. Assistive technology 1998, 10(1), 44-50.

20. Herwig, O. Universal Design: Solutions for Barrier-free Living. Walter de Gruyter. 2008.

21. Georgieff, P. Ambient Assisted Living, Fazit Schriftenreihe, MFG Stiftung Baden-Württemberg, Oktober 2008

22. Jian Li, Yan-jun Zhao, Hui Li, Li-feng Li, Barrier-free interior design for the disabled people Digital Library IEE Xplore 2011 https://ieeexplore.ieee.org/

23. Bendixen, K. Benktzon, M. Design for All in Scandinavia-A strong concept. Applied ergonomics, 2015, 46: 248-257.

24. Alonso, F. The benefits of building barrier-free: a contingent valuation of accessibility as an attribute of housing. European Journal of Housing Policy, 2002 2(1), 25-44.

25. Van Hoof, J.; Boerenfijn, P. Re-Inventing Existing Real Estate of Social Housing for Older People: Building a New De Benring in Voorst, the Netherlands. Buildings 2018, 8, 89.

26. Zhang, B., \& Cheng, J. F. Application of Barrier-free Design Theory in Furniture for Elderly Person. Packaging Engineering 2007 (3) 043.

27. Chen, Ming-Chuan; Pei-Tseng Kung; Hsun-Pi Su; Suh-May Yen; Li-Ting Chiu and Wen-Chen Tsai, Utilization of tooth filling services by people with disabilities in Taiwan, International Journal for Equity in Health 2016 15(1)

28. Ke, Z. D. L. Discrimination of Universal Design and Barrier-free Design. Huazhong Architecture, 2009 (2) 025 .

29. Janner, B.; Delboni, MCC.; Ferreira, TG.; Ponte, AS.; Pommerehn, J. Persons with disabilities: Identifying a scenario for the insertion of the occupational therapist in the interior of Rio Grande. Sul. Revisbrat Interinst. Bras. Ter. Ocup. Rio de Janeiro. 2018, v.2(1), p. 68-84

30. Adamecz-Völgyi, A.; Levay, P.; Bordos, K.; Scharle, A. Impact of a personalised active labour market programme for persons with disabilities, Scandinavian Journal of Public Health 2018, 46(19), 32-48

31. Barriuso, A.L.; Pérez-Marcos, J.; Jiménez-Bravo, D.M.; Villarrubia González, G.; De Paz, J.F. AgentBased Intelligent Interface for Wheelchair Movement Control. Sensors 2018, 18, 1511

32. Barriuso, A.L.; De la Prieta, F.; Villarrubia González, G.; De La Iglesia, D.H.; Lozano, Á. MOVICLOUD: Agent-Based 3D Platform for the Labor Integration of Disabled People. Appl. Sci. 2018, 8,337 . 
33. Kbar, G.; Abidi, M.H.; Hammad Mian, S.; Al-Daraiseh, A.A.; Mansoor, W. A University-Based Smart and Context Aware Solution for People with Disabilities (USCAS-PWD). Computers 2016, 5, 18.

34. Gilart-Iglesias, V.; Mora, H.; Pérez-delHoyo, R.; García-Mayor, C. A Computational Method based on Radio Frequency Technologies for the Analysis of Accessibility of Disabled People in Sustainable Cities. Sustainability 2015, 7, 14935-14963.

35. Brausch, C. Advantages and Feasibility of a Modular Home, Design for All Phases of Life, thesis, Technical University of Kosice, 2015, Slovakia

36. Brausch, C.; Katunský, D. Changing Social Structure in Europe calls for Tailor-made, Barrier-free Living and new Interior Design, Selected Scientific Papers - Journal of Civil Engineering, 2015 10(1) p. 73-82,

37. Brausch, C.; Katunský, D. Eine sich veränderte Gesellschaftsstruktur in Europa fordert eine passgenaue barrierefreie Wohn- und Raumgestaltung. Inter Kultur: Magazin der Auslandsgesellschaft. 2015, 12, p. 18 .

38. Kuboshima, Y.; McIntosh, J.; Thomas, G. The Design of Local-Authority Rental Housing for the Elderly That Improves Their Quality of Life. Buildings 2018, 8, 71.

39. Pošiváková, T.; Hromada, R.; Pošivák, J.; Molnár, L.; Harvanová, J. Selected aspects of integrated environmental management. Annals of agricultural and environmental medicine: AAEM 2018, 25, 3, p. 403-408. DOI: $10.26444 /$ aaem/80908 